spectrum of this compound displayed three sharp singlets due to methyl protons at 2.54 (singlet, $3 \mathrm{H}, \mathrm{SCH}_{3}$ ), 3.82 (singlet, $3 \mathrm{H}, \mathrm{OCH}_{3}$ ), and $3.84 \mathrm{ppm}$ (singlet, $3 \mathrm{H}, \mathrm{OCH}_{3}$ ) and presented the peaks due to five protons bonding at double bonds at 5.81 (doublet, $1 \mathrm{H}$ ), 6.12 (quartet, $1 \mathrm{H}$ ), 7.08 (singlet, $1 \mathrm{H}$ ), 7.36 (quartet, $1 \mathrm{H}$ ), and $9.59 \mathrm{ppm}$ (doublet, $1 \mathrm{H}$ ). The infrared spectrum of this compound showed the absorptions at 1720 and $1650 \mathrm{~cm}^{-1}$ due to the carbonyl band of the esters and the formyl groups. These carbonyl absorptions exhibited at low wave number than the general carbonyl absorption. This phenomenon would be interpreted by partial contribution of a thiapyranium betaine-(II). The ultraviolet spectrum of this compound revealed maxima at $264(4.13)$ and $407 \mathrm{~nm}$ (4.39). From these spectral data and elemental analysis, this compound was assinged to have the structure (II). The formation of II can be explained by assuming the spiro compound (III) as a key intermediate which might be a usual Diels-Alder reaction product of the above reaction.

An outline of a reaction mechanism is shown in Chart 2.

It was a very interesting and new type reaction that a spiro pyridine ring was opened by heating to give a thiapyrano derivative. We have now a plan to study the reaction of the other enamino dithiocarboxylates having a heterocyclic compound with dimethyl acetylenedicarboxylate or the other dienophiles.

Faculty of Pharmaceutical Sciences,
Nagasaki University
Bunkyo-machi, Nagasaki
$\quad$ Received January 23,1974
Yoshinori TOMINAga

Kazumichi Mizuyama

Goro Kobayashi

\title{
Confirmation of 18-Norsteroidal Structure of "Fukujusonorones." Sensitivity of CMR to Configurational Changes
}

Fukujusonorone was the first 18-norsteroid isolated from a natural source, Adonis amurensis Regel et Radd (Ranunculaceae), for which structure $\mathbf{1}$ was tentatively assigned." The sample had the following properties: $\mathrm{mp} 88^{-9}-90^{\circ}$; UV (EtOH) $249 \mathrm{~nm}(\varepsilon 8600)$; CD (EtOH) $250 \mathrm{~nm}(-2.83), 285 \mathrm{~nm}(1.37), 330 \mathrm{~nm}(-0.34)$. The sharp melting point, thin-layer chromatography (TLC) carried out under a variety of conditions, and the proton magnetic resonance (PMR) which exhibited sharp singlets for 19-H $(\delta 1.05)$ and 21-H $(\delta 2.26)$ Me peaks, suggested it to be homogeneous.

The carbon magnetic resonance $(\mathrm{CMR})^{2)}$ spectrum was measured as a further application of $\mathrm{T}_{1}$ techniques and to provide a check on the assigned structure. Surprisingly, the proton noise decoupled (PND) spectrum showed a number of unexpected doublets. The $T_{1}$ technique $^{3}$ ) was applied at this stage in order to facilitate complete assignment of the spectrum by taking advantage of the different $T_{1}$ relaxation times to simplify analysis of thickly populated regions of the spectrum, e.g., $20-40 \mathrm{ppm}$. The partially relaxed Fourier transform (PRFT) spectrum taken at $0.4 \mathrm{sec}$. shows only the $\mathrm{CH}_{2}$ 's as positive peaks (Fig. 1b); the $\mathrm{CH}$ peaks, C-3, 6, 8, 9, and 17 are weakly negative, whereas the carbonyl, quaternary

1) Y. Shimizu, Y. Sato, and H. Mitsuhashi, Experientia, 25, 1129 (1969).

2) A JEOLCO PS-100 instrument was used.

3) K. Nakanishi, V.P. Gullo, I. Miura, T.R. Govindachari, and N. Viswanathan, J. Amer. Chem. Soc., 95, 6474 (1973), and references cited therein. 
and methyl peaks are still strongly negative under these conditions. The CMR fully supports proposed structure 1. In addition, as shown by the asterisks in 1 , the carbons which appear as doublets are those on rings $C$ and $D$, more specifically those surrounding $C-17$, and this suggests that the sample is an epimetic mixture at $\mathrm{C}-17$; no explanation could be advanced for the doublet nature of the $\mathrm{C}-5$ peak.

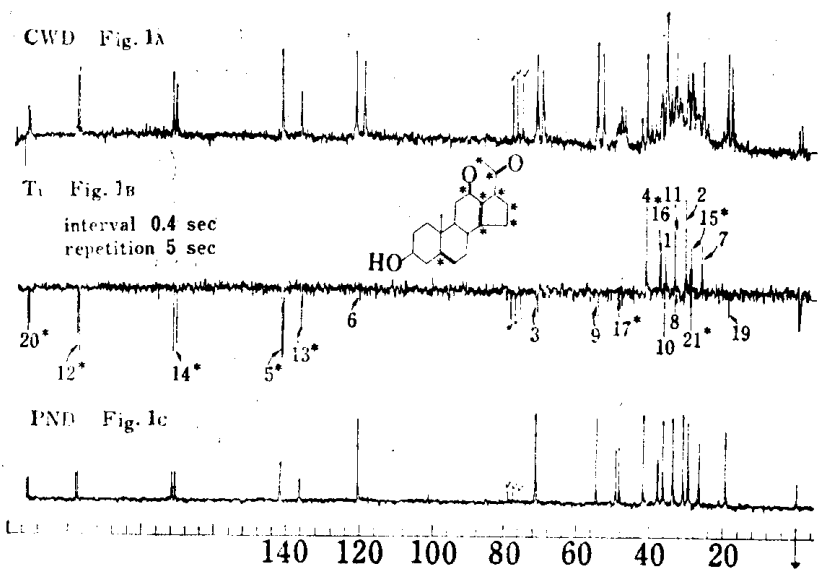

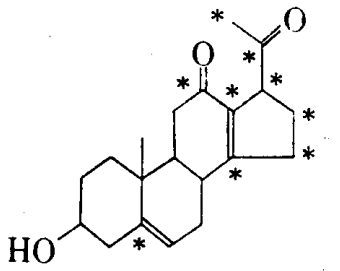

1 fukujusonorones (17 $\alpha$ and $17 \beta$ acetyl)<smiles>C=CC=C1C=CCCC1C</smiles>

$3 \mathrm{~m} / \mathrm{e} 145$

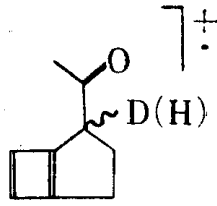

$2 m / e 135(134)$

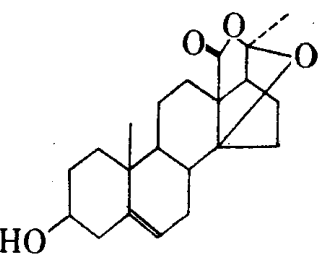

4 adonilide 5 ppm upfield from TMS in the ${ }^{1} \mathrm{H}$ spectrum. The recycle time was $2 \mathrm{sec}$ and the number of scans 9759 .

b) Proton decoupled partially relaxed $\left(\mathrm{T}_{1}\right)$ spectrum at $\imath=0.4$ sec, a recycle time of 5 sec and 3519 scans being employed.

c) Proton noise decoupled (PND) spectrum. The recycle time was $1.8 \mathrm{sec}$ and the number of scans 1522 .

That the doublets were due to the presence of two epimeric compounds was demonstrated by the following: the material could be partially resolved by analytical high pressure liquid chromatography (DuPont Micropak $2^{\prime}$ column, $5 \%$ iso- $\mathrm{PrOH} /$ hexane) into two components present in roughly equal quantities. Mass spectroscopy ${ }^{4)}$ also showed the ready incorporation of deuterium at $\mathrm{C}-17, \leq 10 \%$ upon recrystallization from acetone- $\mathrm{D}_{2} \mathrm{O}$ and $50 \%$ upon treatment with $0.05 \mathrm{~N} \mathrm{H}_{2} \mathrm{SO}_{4}$ in $40 \% \mathrm{EtOH} / \mathrm{D}_{2} \mathrm{O}(\mathrm{v} / \mathrm{v})$ at $60^{\circ}$ for $30 \mathrm{~min}$. (the conditions used to hydrolyze the glycoside during the isolation of fukujusonorone ${ }^{1)}$ ); the low $\%$ incorporation is presumably due to exchange in the mass spectrometer. Location of incorporated $\mathrm{D}$ at C-17 is based on identification of fragments 2 , which arise from a retro-Diels-Alder fragmentation coupled with loss of ketene from rings $\left.C / D,{ }^{5}\right)$ and identification of the non-deuterated fragment 3, which precludes placing the deuterium at C-8.

The possibility that fukujusonorone was an artifact formed from the 12-oxo analogue of adonilide 4 , previously suggested ${ }^{1}$ to be the precursor of $\mathbf{1}$, was eliminated since the original ethanol extract had the same ultraviolet (UV) as that of $\mathbf{1}$.

It is thus apparent that the CMR data fully support the previously proposed structure. Furthermore, it can be seen that while PMR suggests the sample is homogeneous, ${ }^{6)} \mathrm{CMR}$

4) Mass spectrometric analyses were carried out at $70 \mathrm{eV}$ on a DuPont $490 \mathrm{~B}$ mass spectrometer with direct inlet probe at $100^{\circ}$, source $250^{\circ}$ and accelerating voltage $1400 \mathrm{~V}$.

5) H. Budzikiewicz, C. Djerassi, and D.H. Williams, "Mass Spectrometry of Organic Compounds," Holden- Day, Inc., 1967, p. 151.

6) The 15 and 16 protons are hidden in the methylene envelope and the 17-H pattern was uninformative. Examination of models shows that the C/D rings are almost planar so that the 21-H's (and 19-H's) are observed as a singlet due to the similar anisotropic effect of the enone moiety for both $17 \alpha$ and $17 \beta$ acetyl compounds. 
not only readily discerns the presence of two closely related epimers but also locates the epimeric center.

We acknowledge support from National Institutes of Health and National Science Foundation grants.

\author{
Department of Chemistry \\ Columbia University \\ New York, New York 10027 \\ Department of Pharmacognosy \\ College of Pharmacy \\ University of Rhode Island \\ Kingston, Rhode Island 02881
}

\author{
Philippa H. Solomon \\ KOJI NAKANISHI \\ William E. Fallon \\ Yuzuru Shimizu
}

Received February 16, 1974

\section{Occurrence of Novel Type Bufotoxin in Japanese Toad}

The bufotoxin, isolated first from the toad venoms by Wieland, et al., ${ }^{1}$ ) was definitely characterized to be the 3 -suberoylarginine ester of bufogenin by degradative ${ }^{2,3)}$ and synthetic means. ${ }^{4,5)}$ Recently a novel bufotoxin in which the succinoyl residue is substituted for the suberoyl group of the hitherto known conjugated bufadienolide, has been separated from the skin of Japanese toad. ${ }^{6}$ ) We now wish to report the occurrence of an additional new type bufotoxin possessing adipic acid as a dicarboxylic acid moiety in the parotid glands of Bufo vulgaris formosus Boulenger.

One thousand toads collected in the northeastern district of Japan were freezed in dry ice, and the parotid glands were removed and extracted with cold ethanol. The extract was submitted to dry column chromatography on silica gel and eluted with ethyl acetatemethanol $(1: 1)$. The eluate was redissolved in chloroform-methanol-water $(80: 20: 2.5)$ and chromatographed on silica gel impregnated with the aqueous phase. Repeated purification by partition chromatography furnished a bufotoxin fraction which exhibited a single spot on the thin-layer chromatogram. Being subjected to enzymatic hydrolysis with the hog pancreas lipase preparation (Sigma Chemical Co., St. Louis), followed by methylation with diazomethane, this fraction gave a new substance $(\mathrm{Ib}), \mathrm{mp} 185-187^{\circ},[\alpha]_{\mathrm{D}}^{14}+13.6^{\circ}(c=$ 0.11 in $\mathrm{CHCl}_{3}$ ), as colorless prisms (from ether) together with the known methyl ester of cinobufotalin 3-hemisuberate, mp 132.5-134.5 ..$^{\text {? }}$

The spectral inspection of $\mathrm{Ib}$ afforded the following data: $\mathrm{NMR}\left(\mathrm{CDCl}_{3}\right.$ solution) $\delta: 0.80$ $\left(3 \mathrm{H}, \mathrm{s}, 18-\mathrm{CH}_{3}\right), 0.98\left(3 \mathrm{H}, \mathrm{s}, 19-\mathrm{CH}_{3}\right), 1.84\left(3 \mathrm{H}, \mathrm{s}, 16 \beta-\mathrm{OCOCH}_{3}\right), 2.30\left(8 \mathrm{H}, \mathrm{m},-\left(\mathrm{CH}_{2}\right)_{4}-\right)$,

1) H. Wieland and R. Alles, Ber., 55, 1789 (1922); H. Wieland, G. Hesse, and R. Hüttel, Ann., 524, 203 (1936); H. Wieland and H. Behringer, ibid., 549, 209 (1941).

2) H.O. Linde-Tempel, Helv. Chim. Acta, 53, 2188 (1970).

3) K. Shimada, Y. Fujii, E. Mitsuishi, and T. Nambara, Chem. Ind. (London), 1974, 342.

4) G.R. Pettit and Y. Kamano, Chem. Commun., 1972, 45.

5) K. Shimada, Y. Fujii, and T. Nambara, Chem. Ind. (London), 1972, 258; idem, Chem. Pharm. Bull. (Tokyo), 21, 2183 (1973).

6) K. Shimada, Y. Fujii, E. Mitsuishi, and T. Nambara, Tetrahedron Letters, 1974, 467.

7) N. Höriger, D. Živanov, H.H.A. Linde, and K. Meyer, Helv. Chim. Acta, 53, 1993 (1970). 